\title{
An appeal to embryologists
}

\section{The British House of Commons seems bent on passing a bill to prevent some kinds of research. Here is a way in which embryologists and geneticists can help themselves and even help defeat the bill.}

\begin{abstract}
Mr Enoch Powell's already famous bill to prevent the use of fertilized human embryos for any other purpose than the treatment of infertility seems to have carried the British House of Commons with it. The substantial majority for the second reading of the bill two weeks ago, endorsement of the principle, is an embarrassment for the British government, properly anxious to produce a comprehensive piece of legislation to deal with the problems defined in last year's report from the Warnock committee, but which should also have seen the danger that its plans could be so easily
\end{abstract} undermined.

What the House of Commons seems not to appreciate is that it has embarked on an unprecedented and dangerous course, the outright banning of certain kinds of research. Its intention, following $\mathrm{Mr}$ Powell, is that there should literally never be in Britain even the most sober and wellintentioned investigation of human embryos.

But why should research be sacrosanct, especially when it flatly conflicts with what seems to be an absolute moral principle? This is what the 238 Members of Parliament who voted for the Powell bill were asking two weeks ago. What the scientific community must now recognize is that, while there may be arguments about the force of the moral principle, there is very little chance that this substantial body of opinion in the House of Commons will simply melt away. The practical task is somehow to persuade a large group of sensible people, who must constitutionally be supposed to represent a comparable body of opinion in the general population, that some other course of action than $\mathrm{Mr}$ Powell's bill will meet their need.

The starting point must be that research is not sacrosanct. There are already many fields in which investigators do not enjoy untrammelled freedom to do what they like. In most countries, experiments with animals are quite properly regulated with the objective of minimizing the pain that may be suffered in the best-designed experiments. Here the guiding principles are that animals, whose lives are not protected as are those of human beings, must nevertheless not suffer needlessly, which is a goal in its own right but which also protects the investigators concerned from debasement. In genetic manipulation and in work with dangerous pathogens, investigators are free to follow their interests only if they conform with guidelines designed to protect the safety of other people. In most countries, fetal material (as obtained at abortion) can be used, but only with seemly consideration for its source. More to the point, even investigations in which people are the experimental subjects are allowed, but only under the strictest criteria, among which pride of place is taken by the doctrine that the subject must understand what is proposed and must appreciate what risks may be involved. The plain fact is that there are already many fields of research which raise difficult moral problems. In no case has it yet been thought necessary to institute an outright ban. Regulation has been thought sufficient.

The reasons why an otherwise sensible legislature has on this occasion departed from precedent must be understood more clearly. Part of the explanation lies in the title of Mr Powell's bill, the "unborn children (protection) bill". Logician that he is, Mr Powell's argument against regulation rather than an outright ban is easy to predict: embryos are people or potential people who, because of their condition, are unable to give their informed consent. The best hope of winning a better piece of legislation is the likelihood that not many members of the British House of Commons will share this extreme position.

Even a superficial reading of the debate on 15 February in the House of Commons will show that the supporters of the bill span as wide a spectrum of opinion as would be expected. $\mathrm{Mr}$ Powell's acknowledged "deep and instinctive" revulsion from investigations of human embryos was widely shared, while many participants in the debate volunteered the opinion that "scientists must be stopped from playing God". The missing ingredient in the debate was the clear statement of what exactly are the benefits of investigations with human embryos. That is not surprising, for as yet there have been no such investigations.

The most common misapprehension seems to have been the almost entire lack of an understanding of what may be meant by research with human embryos. Within the scientific community, it is too easy to suppose that the implications are generally understood. But the chances are that, for many purposes, mere observation (with the help of a microscope) would suffice. Given the general interest in the early differentiation of embryos, it might also be necessary to separate early embryos into individual cells, perhaps so as to understand the cir- cumstances in which totipotency is lost (but those are investigations on which work with other mammalian embryos might suffice). The immunology of the early embryo, and questions of teratogenicity, might involve adjusting the chemical environment of an embryo in vitro by the addition of identified substances, may of them naturally occurring. In all kinds of investigations, it would be necessary to be able to dissect an embryo after some fixed period of development, perhaps so as to learn something about its genetic structure. Compared with the more lurid suppositions of what the new opportunities in human embryology constitute - schemes for making literally artificial human beings and the like - this is all dull and almost pedantic stuff. Indeed, except in relation to the technology of in vitro fertilization, there seems at present something of a dearth of serious proposals for investigations that would make sense.

Accordingly, those with an interest in these opportunities (and in seeing the debate about the Powell bill take a measured course) are invited to take part in an experiment. The intention is to discover what kinds of investigations with human embryos would, in present circumstances, be carried out. Those willing to participate are asked to send to the editor (in London, in an envelope marked "Embryo Research") a synopsis of a proposed investigation with human embryos, giving a succinct account of the objectives, the reasons for expecting these to be attainable, a brief account of the procedure to be followed (together with an estimate of the numbers of embryos required, controls included) and an explanation why the use of human as distinct from other mamalian embryos is necessary.

Synopses received in the Nature office within one month of the date of this issue and judged suitable for the purpose will be sent to a panel of referees composed along the lines recommended by the Warnock committee. Opinions will be solicited from lay people as well as from researchers and physicians. Submissions as such will not be published, but (with the agreement of the authors) the gist of each proposal will appear together with the opinions of all the referees. Those whose submissions are dealt with in this way will be asked to nominate someone (possibly themselves) to receive a copy of Nature free for the year ahead. The outcome of this experiment may be to put the Powell bill in perspective. 